\title{
Bicanalicular Intubation with the Kaneka Lacriflow for Proximal Lacrimal Drainage System Stenosis
}

This article was published in the following Dove Press journal:

Clinical Ophthalmology

\author{
Sarah W DeParis ${ }^{1,2}$ \\ Clarinda J Hougen' \\ Fatemeh Rajaii (D) \\ Nicholas R Mahoney' \\ 'Department of Ophthalmology, Wilmer \\ Eye Institute, Johns Hopkins Hospital, \\ Baltimore, MD, USA; ${ }^{2}$ Department of \\ Ophthalmology, The Permanente Medical \\ Group, San Rafael, CA, USA
}

Purpose: The Kaneka Lacriflow CL (Lacriflow) bicanalicular lacrimal intubation system was evaluated as a self-retaining alternative to traditional modalities for stenting and dilation of the lacrimal drainage system in proximal lacrimal drainage system stenosis.

Patients and Methods: A retrospective chart review was conducted to assess the use of the Lacriflow system for treatment of patients with punctal and canalicular stenosis. Anesthesia type, operative time, and complications were assessed.

Results: In the time period evaluated, a total of 72 Lacriflow stents were placed in 45 patients, most commonly under intravenous sedation. Stents were left in place for a mean of 145 days, with 9 stents left in place for more than 1 year, and a mean follow-up time of 263 days. Early complications within 90 days included prolapse in 1 stent, symptomatic colonization for 2 stents, and corneal abrasion in 1 stent in a patient with anterior basement membrane dystrophy. Five additional stents developed colonization in the late postoperative period (four of which were more than 1 year after stent placement). The overall complication rate (per stent) at 3 months after surgery was $5.6 \%$ and at all follow-up time points was $13.9 \%$. Operative times were significantly shorter for a cohort of patients undergoing bicanalicular intubation with the Ritleng system $(P=0.015)$.

Conclusion: The Lacriflow bicanalicular stent can be easily placed without general anesthesia. Complication rates are comparable to other bicanalicular intubation systems, but increase with longer time that stents are left in place.

Keywords: bicanalicular intubation, canalicular stenosis, punctal stenosis, Lacriflow, silicone intubation

\section{Introduction}

Epiphora secondary to proximal lacrimal system (punctal and canalicular) stenosis is a common problem seen in the oculoplastic surgery clinic. Punctal stenosis can be treated with snip punctoplasty, but this does not address canalicular stenosis and may disrupt muscles along the canaliculus important for pumping of tears through the nasolacrimal system. ${ }^{1}$ Intubation of the lacrimal drainage system has been described as an alternative method of treatment. ${ }^{2}$ However, monocanalicular stents block flow through the punctum and cannot support the medial canthus. Traditional bicanalicular systems such as Ritleng (FCI Ophthalmics, Pembroke, MA) or Crawford (FCI Ophthalmics, Pembroke, MA) can result in iatrogenic trauma to the canaliculi, distal nasolacrimal duct or nasal anatomy during placement. ${ }^{1}$ In addition, these systems require retrieval of the stent within the nose during placement, often necessitating general anesthesia to protect the airway from bleeding. ${ }^{3}$
Correspondence: Nicholas R Mahoney Department of Ophthalmology, Wilmer Eye Institute, Johns Hopkins Hospital, 600 North Wolfe Street, Baltimore, MD 21287, USA

Tel +| 410955 |III2

Fax + 4106149987

Email nick.mahoney@jhmi.edu 


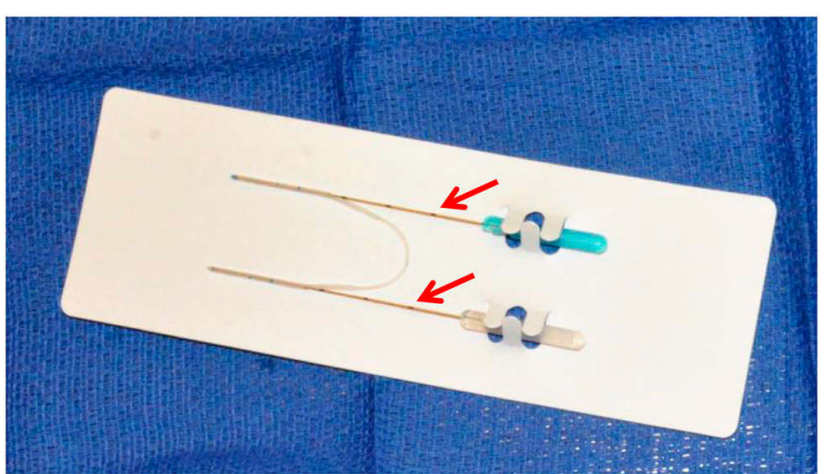

Figure I The Lacriflow bicanalicular stent with a central rod segment and two thicker tube segments, each with a slit several millimeters from the distal end. Two removable metal probes (arrows) are inserted through the slits and allow atraumatic guidance of the self-retaining tube into the nasolacrimal duct.

The Kaneka Lacriflow CL (Lacriflow) (Kaneka Pharma America, New York, NY) system is a revised Nunchakustyle tube with a central rod segment and two thicker tube segments, each with a slit several millimeters from the distal end (Figure 1). ${ }^{4,5}$ The thicker segments allow the tube to be self-retaining without requiring suture placement to hold it in place. A removable metal probe is inserted through the slit and allows guidance of the tube into the nasolacrimal duct. ${ }^{4}$ The tube has a hydrophilic coating that acts to lubricate the surface and promote ease of passage, hypothetically reducing the risk of iatrogenic trauma. This system has been previously described as a minimally invasive treatment of partial nasolacrimal duct obstruction. ${ }^{6}$ Like other bicanalicular intubation systems, the stent acts as a "wick" allowing tears to pass into the punctum around the tube (unlike monocanalicular systems, which completely block the punctum).

Given the shortcomings of widely used bicanalicular intubation systems, a more efficient system of nasolacrimal intubation would be advantageous. In this study, we report our experience with the Lacriflow system for punctal and canalicular stenosis.

\section{Patients and Methods}

A retrospective chart review was conducted of patients at the Wilmer Eye Institute who underwent Lacriflow placement by a single surgeon from January 2015 to July 2017. Adult patients with Lacriflow placement for the indication of proximal lacrimal drainage system stenosis (punctal or canalicular stenosis) were included in the study. Pediatric patients were excluded. Patients with additional diagnoses undergoing concurrent procedures at the same time as Lacriflow placement were included. The Johns Hopkins
Institutional Review Board granted approval for this study, which was HIPAA-compliant and adhered to the tenets of the Declaration of Helsinki. Surgical intubation with the Lacriflow system was performed in the same manner for all patients by a single surgeon (N.R.M.) (Video 1). Topical proparacaine was applied to the operative eye. The puncta were dilated and the Lacriflow tube lubricated with saline. The Lacriflow tube and probe were inserted into the punctum and passed through the canaliculus until a "hard stop" was encountered. The probe was then rotated and passed into the nasolacrimal duct; it was seated such that the blue marking indicating the center point of the tube was visible just outside the punctum. The tube was stabilized with a gauze sponge while the probe was removed. This was performed in the same fashion for the upper and lower canalicular systems. Data were analyzed using two-tailed unpaired Student's $t$-test.

\section{Results}

Seventy-two stents placed in 45 adult patients with punctal or canalicular stenosis were included in the analysis after exclusion of three pediatric patients with congenital nasolacrimal duct obstruction. Patients had a mean age of 67 years with a range of 20 years to 91 years. A number of patients had additional diagnoses, the most common of which were ectropion (22 patients), dermatochalasis (four patients), conjunctival lesion (four patients), ptosis (three patients), and partial nasolacrimal duct obstruction (two patients). Lacriflow stents were retained for a mean of 145 days with a range of 1 day to 580 days. Nine stents were left in place for more than 1 year, most often in patients with severe punctal or canalicular stenosis. Mean followup time was 263 days with a range of 13 to 817 days.

Stents were placed under intravenous sedation for 40 stents (55.6\%) and local anesthesia for 4 stents (5.6\%). Twenty-eight stents (38.9\%) were placed under general anesthesia; all of these patients underwent concurrent additional procedures. The most common additional procedures performed under general anesthesia were full-thickness skin graft (three patients), conjunctival procedures such as lesion excision or biopsy (three patients), and anterior orbitotomy (two patients). There were a variety of other additional procedures performed, such as mullerectomy, lateral tarsal strip, electroepilation, balloon dacryoplasty, and combined cases with other services such as head and neck surgery for septoplasty. The punctum was not incised during stent placement or in any concurrent procedures. Nine patients (14 stents) in this cohort underwent Lacriflow insertion alone 
without concurrent additional procedures; these patients all had a diagnosis of punctal or canalicular stenosis only.

We investigated a comparison group of bicanalicular intubation using the Ritleng system by another experienced oculoplastic surgeon at the same institution for isolated punctal or canalicular stenosis within the same time period. For nine patients, mean operative time for the Ritleng system was 13.8 mins (range 8.5 to 39.5 mins), which was significantly longer than in Lacriflow patients $(P=0.015)$. Of note, four patients $(44.0 \%)$ in the Ritleng group required general anesthesia compared to none of the Lacriflow patients.

Complications are shown in Table 1 . Two stents $(2.8 \%)$ in two patients prolapsed and were removed, one on the first postoperative day and one at 113 days after surgery. Six stents $(8.3 \%)$ in 4 patients had buildup of debris on the tubes requiring removal. This occurred more than 1 year after placement for four stents. One of these patients had debris noted on bilateral stents at 580 days after surgery, and declined treatment with drops due to pregnancy, so the stents were removed. For the remaining two stents, this occurred between 1 and 2 months after surgery. One additional stent in one patient had debris buildup and irritation noted at 140 and 269 days after surgery and was treated with topical antibiotic drops alone without tube removal. One patient had a corneal abrasion 30 days after stent placement thought to be secondary to a known diagnosis of anterior basement membrane dystrophy (as the stent was in proper position), and was treated with a bandage contact lens. The overall complication rate (per stent) at 3

Table I Complications of Lacriflow Stent Placement. Shown are Complications of Lacriflow Stent Placement at All Time Points After Surgery, Which Occurred for 10 Stents in 8 Patients. Four Complications (5.6\%) Occurred Within the 90-Day Early Postoperative Period. The Overall Complication Rate per Stent at All Time Points Was 13.9\%

\begin{tabular}{|l|l|l|l|}
\hline $\begin{array}{l}\text { Patient } \\
\text { Number }\end{array}$ & Complication & $\begin{array}{l}\text { Timing (Days } \\
\text { After Surgery) }\end{array}$ & Treatment \\
\hline 1 & Stent prolapse & I & Stent removal \\
2 & Corneal abrasion & 30 & $\begin{array}{l}\text { Bandage contact } \\
\text { lens }\end{array}$ \\
3 & Stent colonization & 46 & Stent removal \\
4 & Stent colonization & 52 & Stent removal \\
5 & Stent prolapse & 113 & Stent removal \\
6 & Stent colonization & 140,269 & Antibiotic drops \\
3 & Stent colonization & 410 & Stent removal \\
7 & Stent colonization & 558 & Stent removal \\
8 & Stent colonization & 580 & Stent removal \\
8 & Stent colonization & 580 & Stent removal \\
\hline
\end{tabular}

months after surgery was $5.6 \%$. The overall complication rate for all stents at all follow-up time points was $13.9 \%$. There were no other complications including no punctal erosion, intraoperative or postoperative bleeding. Of the eight patients (10 stents) that developed complications, 3 patients underwent Lacriflow stent placement alone (38.5\%), and 5 patients $(62.5 \%)$ had additional procedures performed at the time of surgery. These additional procedures varied widely and included upper blepharoplasty, eyelid lesion excision, conjunctivoplasty, canalicular repair, and ectropion repair.

\section{Discussion}

Bicanalicular silicone intubation using traditional systems such as Crawford or Ritleng carries risk of trauma to the nasolacrimal system during placement with possible creation of false passages in multiple locations along the drainage pathway. These systems often require retrieval of the stent in the nose during placement with possible need for general anesthesia for airway protection or very deep sedation for patient comfort due to manipulation of the nasal passages. The Lacriflow system is an alternative method of bicanalicular intubation that may circumvent these issues, as it is easy to insert for both patient and surgeon, with limited capacity to cause undo damage to the tear system or nasal passageways.

Complication rates for traditional bicanalicular intubation systems greatly vary, with rates from $0 \%$ to $41 \%$ described in the literature. ${ }^{7-13}$ Complications can include stent prolapse or extrusion, punctal erosion (or "cheese wiring"), conjunctivitis, mucoid debris accumulation on the stent (or colonization), granuloma and fistula formation, and nasal bleeding. ${ }^{8,9}$ Anderson and colleagues reported on complication rates of Guibor tubes in patients with all types of obstructions of the nasolacrimal system, and noted a $29 \%$ complication rate with this system. ${ }^{8}$ Other studies have reported much lower rates. ${ }^{2,14}$ In an earlier study using a Nunchaku-style stent (predecessor of the Lacriflow system) for complete nasolacrimal duct obstruction, an overall complication rate of $35 \%$ was reported, including exposure of the stent end from the nose in $7.4 \%$ and punctal erosion in $18.5 \%{ }^{4}$ In the previous report of the Lacriflow system, stents were left in place for 90 days before removal in the office with an additional 1-month follow-up. Stents were removed prematurely due to complications in seven patients, with four cases $(5 \%)$ of stent prolapse and two cases $(3 \%)$ of conjunctivitis noted. ${ }^{6}$ In our series, Lacriflow stents were well 
tolerated with a 3-month complication rate of $5.6 \%$ and overall complication rate of $13.9 \%$ despite stents being left in place longer (mean 145 days), with longer follow-up time (mean 263 days). Using a 90-day postoperative time point for comparison purposes, three patients $(4.2 \%)$ in this study had early tube removal prior to 90 days due to complications, which is similar to the prior Lacriflow study (Table 1). Stent prolapse requiring premature removal occurred in two patients $(2.8 \%)$, which is also similar to the prior Lacriflow study. ${ }^{6}$ Of note, there were no cases of tube exposure from the nose or punctal erosion noted in either this study or the previous report of the Lacriflow system, which may be due to the self-retaining nature of the stent. ${ }^{6}$

In patients with severe punctal or canalicular stenosis thought to be prone to re-stenosis upon tube removal, it is the authors' practice to leave stents in place for a longer time period to achieve long-term patency and dilation. As such, the duration of stent retention in this study (mean of 145 days with a range of 1 day to 580 days) is longer than stent retention times in many other studies. ${ }^{6,10-12}$ However, the preferred amount of time for stent retention varies based on the indication for tube placement as well as surgeon preference and training. ${ }^{9}$ Though the 90 -day complication rate in this study is similar to the prior Lacriflow study, the overall complication rate in our study of $13.9 \%$ is higher, possibly due to the longer follow-up time and longer time that the stents were retained.

Several prior studies of other bicanalicular stent systems with longer stent retention times have reported complication rates. ${ }^{2,9,13,15}$ Ahmed and coauthors evaluated planned longterm stent placement in patients with punctal stenosis secondary to trachoma, with a mean time for stent retention of $29.6 \pm 10.2$ months. They reported complications requiring stent removal in $23.1 \%$, and hypothesized that longer stent retention time may be helpful in patients prone to restenosis after tube removal. ${ }^{15}$ Veloudios et al evaluated long-term retention of Crawford bicanalicular nasolacrimal stents for a variety of indications, with a follow-up time of 3 to 66 months. They noted a $41 \%$ complication rate in the first 3 months that decreased to $10 \%$ after 6 months. Eleven patients retained the tubes for more than 36 months with no reported complications, and the authors concluded that stents could be left in place "indefinitely" in some patients. ${ }^{9}$ Moscato and coauthors investigated bicanalicular silicone intubation for treatment of functional nasolacrimal duct obstruction with a mean time to stent removal of 4 months, longest stent retention time of 24 months, and a complication rate of $9.1 \% .{ }^{13}$ Connell and colleagues reported long term follow-up of bicanalicular intubation for canalicular and nasolacrimal duct obstructions, with stents left in place for 3-10 months (mean 4.8 months) and a mean follow-up time of 69.7 months. The authors reported no tube related complications. ${ }^{2}$ Our long-term complication rate is comparable to several of these studies, but the reported rates vary widely. This may be due to differences in stent systems, operative technique, or criteria used to define complications. Clearly, further prospective evaluation is needed comparing stent systems with standardization of variables such as the patient populations, indication for stenting, complication definitions, stent retention time, and follow-up time.

The most common complication in both the early postoperative period (less than 90 days) and late postoperative period (more than 90 days) in this study was symptomatic colonization of the stent with buildup of debris adherent to the stent surface noted clinically and resulting eye irritation. This occurred in the early (90-day) postoperative period in two stents (two patients); the stents were removed as treatment. One stent developed colonization at 140 and 269 days postoperatively and was successfully treated with antibiotic drops for both occurrences. Four stents in three patients developed late colonization more than 1 year after stent placement and required removal. Indeed, the likelihood of developing colonization seems to increase with greater amount of time that the stents are retained. In the nine patients in this study with stents left in place for more than 1 year, the complication rate was much higher (44.4\%) due to late colonization. Similarly, Veloudios and coauthors noted that "dirty tubes" or stent colonization was the most common late complication. ${ }^{9}$ This may be corroborated by scanning electron microscopy, which reveals biofilm formation on nasolacrimal stents. ${ }^{16,17}$ Biofilms have been noted to form on Monoka stents as early as 6 weeks after stent placement and are more extensive with longer stent retention time. ${ }^{16}$ For Crawford stents retained for greater than 1 year in patients lost to follow-up after DCR, biofilms were also noted to be more extensive with greater stent retention time. ${ }^{17}$ However, in both of these studies, none of the patients showed clinical signs or symptoms of infection, and the clinical implications of the observed biofilms are not well understood. ${ }^{16,17}$ The Lacriflow tube is made of a different polymer than Monoka and Crawford stents, which could hold different properties in relation to biofilm formation. ${ }^{6}$ Future studies are indicated comparing Lacriflow stents to other bicanalicular systems in 
the rates of clinically evident colonization as well as biofilm formation.

In this series, Lacriflow stents were primarily placed with intravenous sedation, particularly when there were no additional concurrent procedures. Prior studies of Nunchaku-style tubes describe stent placement primarily under local anesthesia with infraorbital nerve block and topical anesthetic, with some cases requiring intravenous sedation or general anesthesia. ${ }^{4,6,18}$ However, these studies included a variety of indications such as complete nasolacrimal duct obstruction and distal obstructions, which may affect anesthesia choice. In earlier studies of traditional bicanalicular intubation systems, general anesthesia was often used. ${ }^{3}$ Although these systems can also be placed under intravenous sedation, the level of sedation required is very deep given the need for stent retrieval in the nose during placement, and this leaves the airway unprotected in the event of bleeding. In addition, occasional difficulty retrieving the stent in the nose during placement has been reported, and some authors recommend using nasal endoscopy for assistance in tube placement with patients under local anesthesia or sedation. ${ }^{2,3}$

In previous studies of Nunchaku-style tubes, operative times ranged from 7 to 10.5 mins when reported. ${ }^{4,18}$ However, the indication for tube placement varied and often included distal and complete nasolacrimal duct obstruction, which may influence operative time., ${ }^{48}$ Our mean operative time of $4.6 \mathrm{mins}$ is comparable to these studies and was significantly shorter compared to the Ritleng system, but further investigation is needed with larger sample sizes. The authors have noted exceptional ease of placement of the Lacriflow stent in the true tear system. Given the flexible nature of the insertion probe and the hyper-lubricated hydrophilic surface, the tube seems to "find" the tear system on its own (Video 1). This may reduce risk of iatrogenic trauma to the nasolacrimal system and allows for relatively rapid tube insertion. In cases where the stent mounted on the flexible probe fails to easily "find" the natural duct, the tubing can be advanced 2 to $3 \mathrm{~mm}$ forward from the distal end of the stylet probe, which often results in success. In addition, the Lacriflow system is effective for cases of combined proximal stenosis and canalicular laxity, where it functions as a bicanalicular cerclage. The tube is quickly and easily removed in the office without need for rotation for retrieval of a fixation suture. Although pediatric patients were not included in this study, the authors have noted easy of removal of this tube in the office in young children without need for anesthesia.
At the time of writing, the Lacriflow stent costs $\$ 185$ compared to $\$ 85$ for Crawford and $\$ 80$ for Ritleng. Unlike other bicanalicular tubes, the only other instrumentation needed is a punctal dilator, and there is no retrieval hook or additional insertion probe. Given the differences in equipment, operative time and anesthesia, the savings in time and supplies is likely more than compensatory for the price difference of the Lacriflow stent.

There are several drawbacks to this study. Due to the retrospective nature of the study, consistent documentation of patient symptoms (epiphora) was not always available. In addition, many patients in this study underwent multiple additional concurrent procedures (such as ectropion repair, full-thickness skin graft, and others), which confound assessment of symptomatic improvement and operative time. As such, improvement in epiphora was unable to be evaluated, and the group in which operative time was assessed was quite small. Also, different surgeons performed the procedures in the Lacriflow and Ritleng groups, which may confound results, though both were senior fellowshiptrained oculoplastic surgeons. The surgeon performing Lacriflow placement now uses this device almost exclusively for punctal and canalicular stenosis due to the ease of its use, no longer using alternative stent systems during the time period studied. This prevented comparison to other bicanalicular systems within the same surgeon's practice. Future prospective studies are needed with larger groups of patients, standardized indications for stent placement, and comparison to other bicanalicular stent systems assessing intraoperative trauma, complications, and operative time. Additional future studies of the Lacriflow system could also assess improvement in epiphora, particularly in cases of isolated punctal or canalicular stenosis.

\section{Conclusion}

The Lacriflow is a self-retaining bicanalicular system that can be easily placed without general anesthesia and with a complication rate that is comparable to other bicanalicular stenting systems. Further study is needed, but this system can be considered as an alternative to other bicanalicular systems for proximal lacrimal drainage system stenosis.

\section{Disclosure}

None of the authors have any financial interests to disclose. No conflicting relationship exists for any author. 


\section{References}

1. Hussain RN, Kanani H, McMullan T. Use of mini-monoka stents for punctal/canalicular stenosis. Br J Ophthalmol. 2012;96(5):671-673. doi:10.1136/bjophthalmol-2011-300670

2. Connell PP, Fulcher TP, Chacko E, O'connor MJ, Moriarty P. Long term follow up of nasolacrimal intubation in adults. Br J Ophthalmol. 2006;90(4):435-436. doi:10.1136/bjo.2005.084590

3. Fulcher T, O'Connor M, Moriarty P. Nasolacrimal intubation in adults. Br J Ophthalmol. 1998;82(9):1039-1041. doi:10.1136/bjo.82. 9.1039

4. Inatani M, Yamauchi T, Fukuchi M, Denno S, Miki M. Direct silicone intubation using Nunchaku-style tube (NST-DSI) to treat lacrimal passage obstruction. Acta Ophthalmol Scand. 2000;78 (6):689-693. doi:10.1034/j.1600-0420.2000.078006689.x

5. Kurihashi K. Bicanalicular silicone intubation using three-piece silicone tubing: direct silicone intubation. Ophthalmologica. 1993;206 (2):57-68. doi:10.1159/000310365

6. Silbert DI. Success rate of placement of a bicanalicular stent for partial nasolacrimal obstruction in adults under local, monitored anesthesia care and general anesthesia. Saudi J Ophthalmol. 2017; 31(3):140-144. doi:10.1016/j.sjopt.2017.06.002

7. Lauring L. Silicone intubation of the lacrimal system: pitfalls, problems and complications. Ann Ophthalmol. 1976;8(4):489-498.

8. Anderson RL, Edwards JJ. Indications, complications and results with silicone stents. Ophthalmology. 1979;86(8):1474-1487. doi:10. 1016/S0161-6420(79)35374-X

9. Veloudios A, Harvey JT, Philippon M. Long-term placement of silastic nasolacrimal tubes. Ophthalmic Surg. 1991;22(4):225-227.

10. Park J, Kim H. Sequential probing and dilatation in canalicular stenosis. Graefes Arch Clin Exp Ophthalmol. 2015;253(11):20 07-2013. doi:10.1007/s00417-015-3151-7
11. Chen D, Li N, Wan P, et al. A novel procedure for treating canalicular obstruction by re-canaliculisation and bicanalicular intubation. $\mathrm{Br}$ J Ophthalmol. 2012;96(3):366-369. doi:10.1136/bjo.2011.202200

12. Andalib D, Nabie R, Abbasi L. Silicone intubation for nasolacrimal duct stenosis in adults: monocanalicular or bicanalicular intubation. J Craniofac Surg. 2014;25(3):1009-1011. doi:10.1097/SCS.0000000 000000708

13. Moscato EE, Dolmetsch AM, Silkiss RZ, Seiff SR. Silicone intubation for the treatment of epiphora in adults with presumed functional nasolacrimal duct obstruction. Ophthalmic Plast Reconstr Surg. 2012;28(1):35-39. doi:10.1097/IOP.0b013e318230b110

14. Merbs SL, Harris LL, Iwamoto MA, Iliff NT. Prevention of prolapsed silicone stents in lacrimal intubation using an intrasac fixation suture. Arch Ophthalmol. 1999;117(8):1092-1095. doi:10.1001/archopht.11 7.8.1092

15. Ahmed RA, Kamal AM, Zayed MA. Evaluation of planned bicanalicular nasolacrimal tube retention in treating punctal stenosis or occlusion secondary to trachoma. Orbit. 2017;36(4):208-214. doi:10. 1080/01676830.2017.1337160

16. Ali MJ, Baig F, Lakhsman M, Naik MN. Scanning electron microscopic features of extubated Monoka stents. Ophthalmic Plast Reconstr Surg. 2017;33(2):90-92. doi:10.1097/IOP.0000000000000 610

17. Ali MJ, Baig F, Lakshman M, Naik MN. Scanning electron microscopic features of nasolacrimal silastic stents retained for prolong durations following dacryocystorhinostomy. Ophthalmic Plast Reconstr Surg. 2016;32(1):20-23. doi:10.1097/IOP.000000000000 0395

18. Mimura M, Ueki M, Oku H, Sato B, Ikeda T. Indications for and effects of Nunchaku-style silicone tube intubation for primary acquired lacrimal drainage obstruction. Jpn J Ophthalmol. 2015;59 (4):266-272. doi:10.1007/s10384-015-0381-5
Clinical Ophthalmology

\section{Publish your work in this journal}

Clinical Ophthalmology is an international, peer-reviewed journal covering all subspecialties within ophthalmology. Key topics include: Optometry; Visual science; Pharmacology and drug therapy in eye diseases; Basic Sciences; Primary and Secondary eye care; Patient Safety and Quality of Care Improvements. This journal is indexed on PubMed
Central and CAS, and is the official journal of The Society of Clinical Ophthalmology (SCO). The manuscript management system is completely online and includes a very quick and fair peer-review system, which is all easy to use. Visit http://www.dovepress.com/ testimonials.php to read real quotes from published authors. 